\title{
A Rare Case of Cutaneous Gamma Delta T-Cell Lymphoma With Complete Body Involvement
}

\author{
Rahul Anila, d, e, Sana Grover ${ }^{b, d}$, Adarsh Hiremath ${ }^{c, d}$
}

\begin{abstract}
A 57-year-old female presented to the emergency department of our hospital with painful skin lesions since 3 months. On examination, ulcerating tumors and plaques occupied $100 \%$ of her body and enlarged firm left axillary lymph nodes were present. On imaging, PET scan revealed hypermetabolic cutaneous lesion, and hyperactive $\mathrm{B} / \mathrm{L}$ axillary, inguinal and intra-parotid lymph nodes. Punch biopsy from right medial thigh skin lesion showed phenomenon of epidermotropism. PCR studies showed strong expression of TCR gamma by atypical cells. FNAC of axillary lymph node and bone marrow biopsy was negative. Based on histo-immunological evidence and dermatologist input, the diagnosis of cytotoxic cutaneous gamma delta T-cell lymphoma (CGDTCL) was made. Patient received five cycles of total skin electron beam therapy. Contrary to the present literature that suggests that cutaneous gamma delta T-cell lymphomas are resistant to chemotherapy and radiation, our patient responded very well to total skin electron beam radiation therapy. The tumors on her body flattened with complete resolution of pain and pruritis. This case report summarizes the unusual presentation of CGDTCL and response to treatment.
\end{abstract}

Keywords: Cutaneous T-cell lymphoma; Mycosis fungoides; T-cell receptor gamma

\section{Introduction}

Cytotoxic cutaneous gamma delta T-cell lymphoma (CGDT$\mathrm{CL}$ ) is a rare aggressive tumor that has recently been identified as a separate entity in WHO 2008 classification [1]. It involves

Manuscript accepted for publication July 07, 2016

aYale School of Medicine, Yale University, Lippard Laboratory of Clinical Investigation, Room \#916, 15 York Street, New Haven, CT 06510, USA

${ }^{b}$ MD Anderson Cancer Center, University of Texas, 1400 Pressler St, Houston, TX 77030, USA

'Department of Medicine, Levine Cancer Institute, University of North Carolina, 1021 Morehead Medical Drive, Charlotte, NC 28204, USA

${ }^{\mathrm{d}}$ All authors contributed equally to this work.

${ }^{e}$ Corresponding Author: Rahul Anil, Yale School of Medicine, Yale University, Lippard Laboratory of Clinical Investigation, Room \#916, 15 York Street, New Haven, CT 06510, USA. Email: drrahulanil@gmail.com

doi: http://dx.doi.org/10.14740/jmc2584w cases which were previously categorized as subcutaneous panniculitis like T-cell lymphoma with gamma delta T-cell phenotype. Gamma delta T-cell lymphomas have been separated from alpha beta phenotype on the basis of carrying a poorer prognosis, decreased survival, more occurrence of necrotization, ulceration and association with hemophagocytic syndrome $[2,3]$. There have been a few case reports of CGDTCL, and according to literature, CGDTCL has been seen to commonly involve the extremities, but to our knowledge, this is the first case with such extensive involvement of the body involving scalp, head and toes with ulcero-necrotic nodules. The rate of spread of lesion in our case from a single bump on cheek to whole body involvement in just 3 months points towards an aggressive course. Therefore, a rare case of CGDTCL presenting with widespread ulcero-necrotic lesions involving whole body with atypical cells expressing only CD4 positivity, responded very well to radiation therapy, that contradicts typical presentation and behavior.

\section{Case Report}

A 57-year-old African American female presented to the emergency department of our hospital with painful skin lesions since 3 months. She reported that it started as a spot which was a red bump with a white center on her left cheek 3 months ago and then progressed to pruritic, painful and ulcerative lesions all over her body, including scalp, palms and soles. The lesions remained persistent throughout 3 months. On examination, the patient had tender, red purple nodules, some crusted and few ulcerating with fouls smelling discharge all over her body, including scalp, palms and soles. She also had a large ulcer on her left cheek, with rolled borders and purulent discharge. Lymph nodes of left axillary region were firm and enlarged. There was no hepatosplenomegaly. Rest of the physical examination was unremarkable.

$\mathrm{CT}$ scan of chest and abdomen showed non-specific B/L pleural effusion without any malignant internal organ involvement. Whereas PET scan revealed innumerable hypermetabolic cutaneous lesions consistent with her presentation and hyperactive $\mathrm{B} / \mathrm{L}$ axillary, inguinal and intra-parotid lymph nodes. FNAC of axillary lymph nodes and biopsy of bone marrow were negative for lymphoma or any other malignancy. Histopathology of biopsied skin lesion showed proliferation of large lymphocytes with irregular nuclei, demonstrating a phenomenon called epidermotropism (Fig. 1). Immunophenotyping study on paraffin sections showed strong expression of CD3 


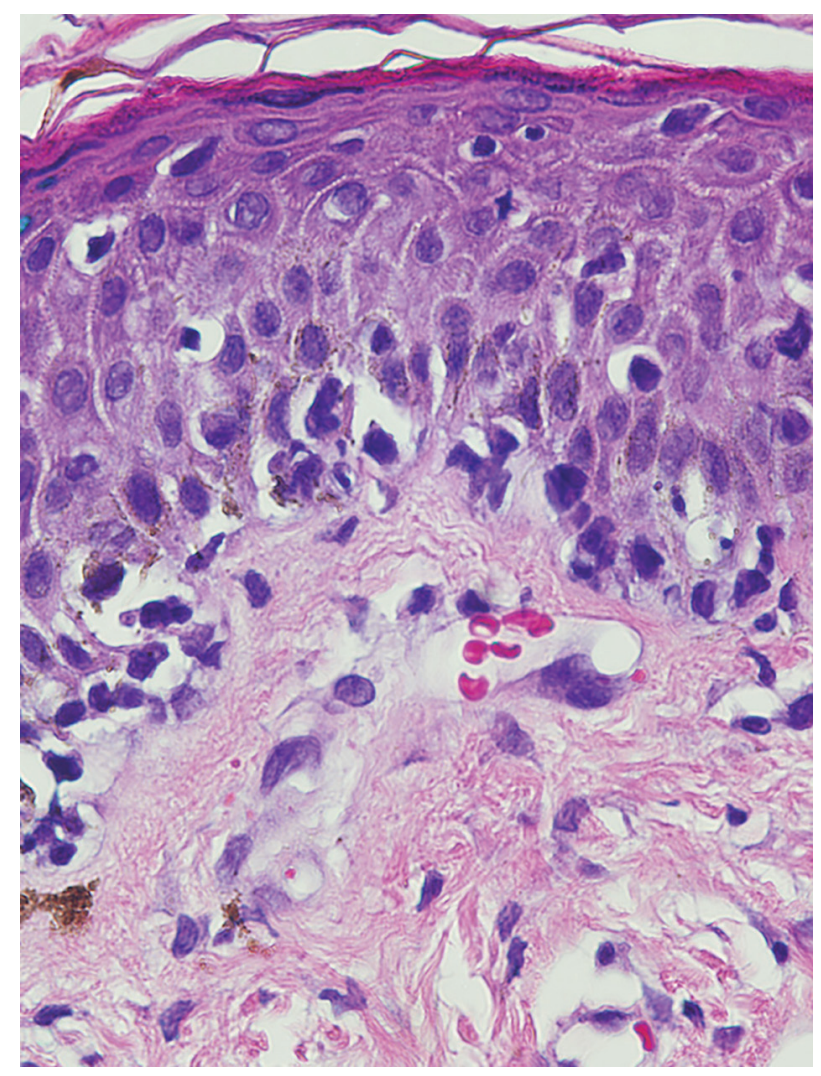

Figure 1. Skin biopsy specimen under higher power of magnification of large, atypical lymphocytes demonstrating epidermotropism (hematoxylin-eosin, magnification, $\times 40$ ).

(Fig. 2) with weak and focal expression of $\mathrm{CD}^{+}$by the atypical cells (Fig. 3). $\mathrm{CD}^{+}$is expressed by scattered lymphocytes with loss of CD7. Expression of both perforin and granzyme indicates cytotoxic phenotype. No significant expression of CD25 was seen. PCR studies showed strong expression of TCR gamma by atypical cells (Fig. 4) and small lymphocytes expressed TCR beta. Flow cytometry showed minute atypical $\mathrm{CD}^{+} \mathrm{T}$ cells of uncertain significance. Complete blood count showed normal leukocyte and RBC count with no eosinophilia. EBV, HTCL, HIV, and HSV tests were all negative.

Patient was treated with ciprofloxacin and metronidazole IV for 14 days, and minocycline for a month. Wound care was done with normal saline, dilute hibiclens wash twice daily and $1 \%$ silverdene ointment. Total skin electron beam therapy (TSEBT), a definitive dose of $36 \mathrm{~Gy}$, was given. Throughout her hospitalization, the patient's condition was stable and improved by above therapy. Patient responded very well to radiation therapy and in remission now. Later, stem cell transplant team has made the recommendations for stem cell transplant.

\section{Discussion}

CGDTCL is an extremely rare lymphoma. It comprises of only $1 \%$ of primary cutaneous lymphomas and has finally been incorporated as a definitive disease entity in the latest WHO clas-

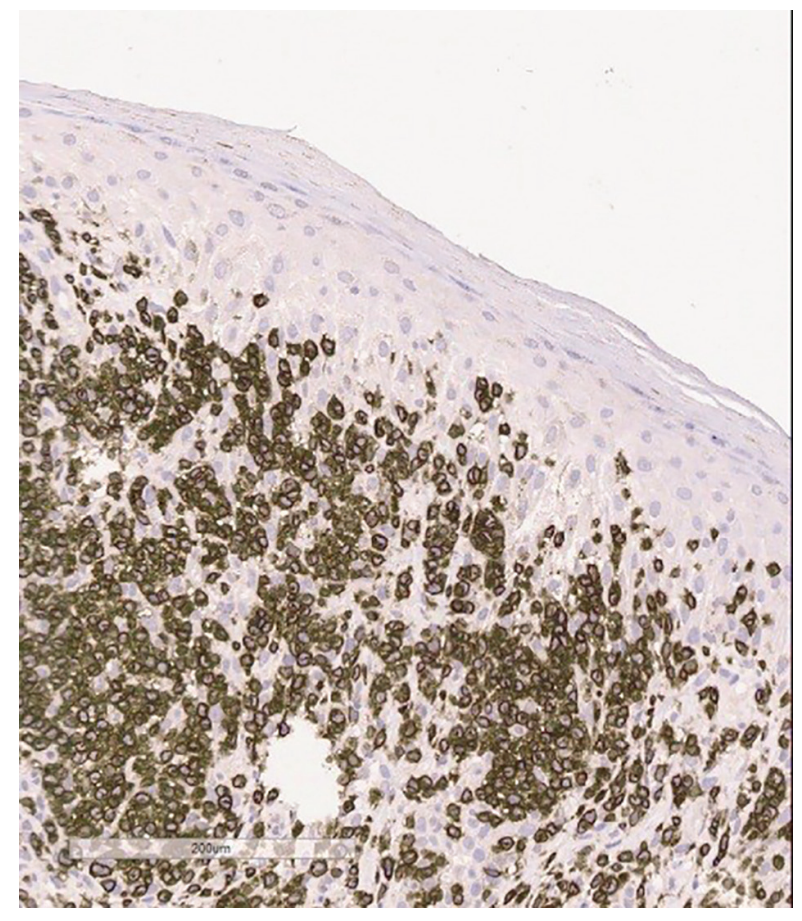

Figure 2. Skin biopsy specimen shows dermal infiltrate consisting mainly of CD3 positive cells on immunophenotyping.

sification of lymphomas [1, 4]. CGDTCL presents with deeply embedded plaques, patches, nodules often with ulceration and necrosis in adults with equal distribution in both sex, commonly involving the extremities [2-5]. There can also be involvement of mucosal and other extra nodal sites, but involvement of lymph nodes, spleen and bone marrow is uncommon [6]. Presence of such clinical features without previous history of lesions, suggestive of mycosis fungoides should arouse suspicion of CGDTCL. Previous case reports of involvement of brain and lungs have shown aggressive clinical course [7-9], but to our knowledge, there has been no case reported of such widespread skin lesions involving whole body, without any internal organ involvement.

CGDTCL has varied histological presentations including epidermotropic, dermal and subcutaneous. There is often more than one histological pattern present in different biopsy specimen from the same patient or sometime within a single biopsy specimen $[3,10]$. Histology may reveal proliferation of small, medium or large pleomorphic lymphocytes and can be associated with intra-epidermal vesiculation, necrosis, angiocentricity and angiodestruction [11]. Immunophenotypically, the tumor cells express CD3, CD2, CD56 (NK cell marker) with or without CD7 and strong expression of cytotoxic proteins ( $\mathrm{T}$ cell intracellular antigen, granzyme, perforin). The cells are beta $\mathrm{F} 1$-ve, lack $\mathrm{CD} 4^{+}$and $\mathrm{CD} 8^{+}$, though $\mathrm{CD} 8^{+}$may be expressed in some cases $[3,12]$. Our patient had CGDTCL with a rare phenotype of atypical cells positive for $\mathrm{CD} 4^{+}$. In frozen sections, the tumor cells are strongly positive for TCR delta. Absence of beta F1 may be used to infer the origin of a gamma delta, if paraffin sections are available [5, 13]. Genetic clonal rearrangement occurs for TCR gamma gene which can 


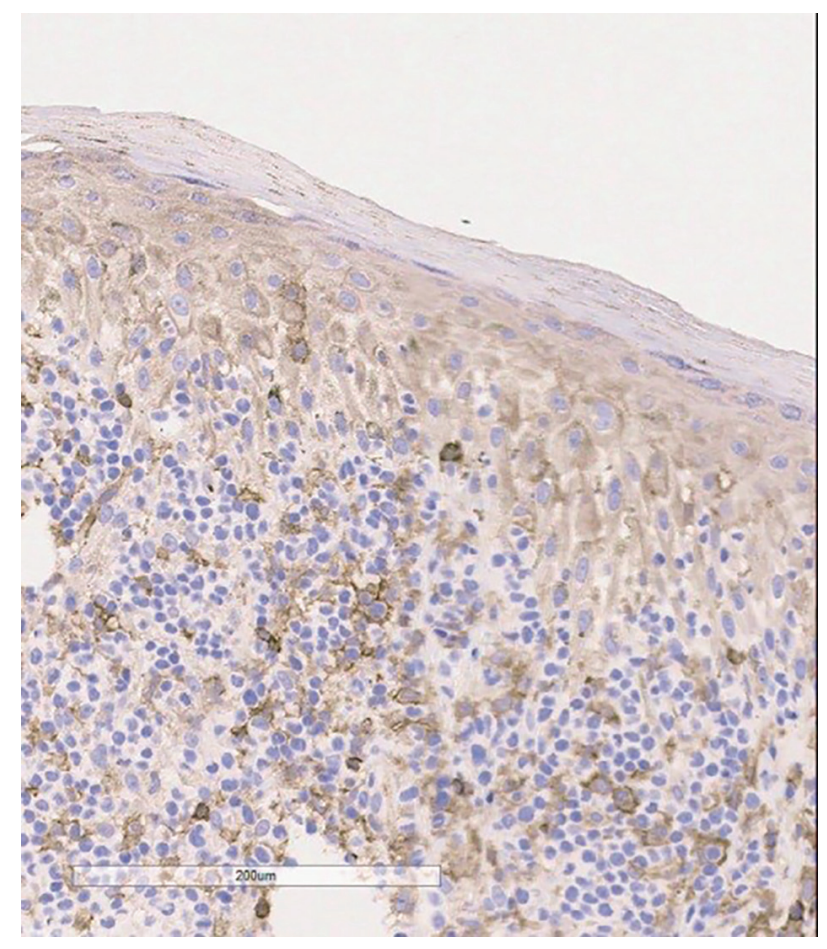

Figure 3. Skin biopsy specimen shows weak CD4 expression by atypical cells on immunophenotyping.

be confirmed with PCR.

CGDTCL is a belligerent disease which is resistant to treatment with multi-agent chemotherapy and radiation $[3,5,6]$. A study by Jorge et al concluded that $33(\mathrm{n}=104)$ patients who tested positive for CGDTCL showed decreased survival when CGDTCL histologically involves the subcutaneous fat in comparison to only epidermal/dermal involvement $(\mathrm{P}<0.0001)[3$, 11]. Results of patients treated with systemic chemotherapy were disappointing. Allogenic stem cell transplantation is the ultimate treatment option for such highly aggressive and lethal lymphoma by literature [14]. Incongruous to results of previous studies in literature, our patient was treated with TSEBT and responded very well. After radiation, her lesions were resolved and in remission now.

\section{Conclusion}

In conclusion, we emphasize that CGDTCL not only presents involving extremities and less common mucosa and extra nodal sites but also with whole body involvement. Clinical features suggesting of mycosis fungoides should arouse the suspicion of CGDTCL. Sometimes, CGDTCL can have atypical cells expressing only CD4 positivity [3] responding very well to radiation therapy in contrast to present literature.

\section{Conflicts of Interest}

All authors declare no conflicts of interest.

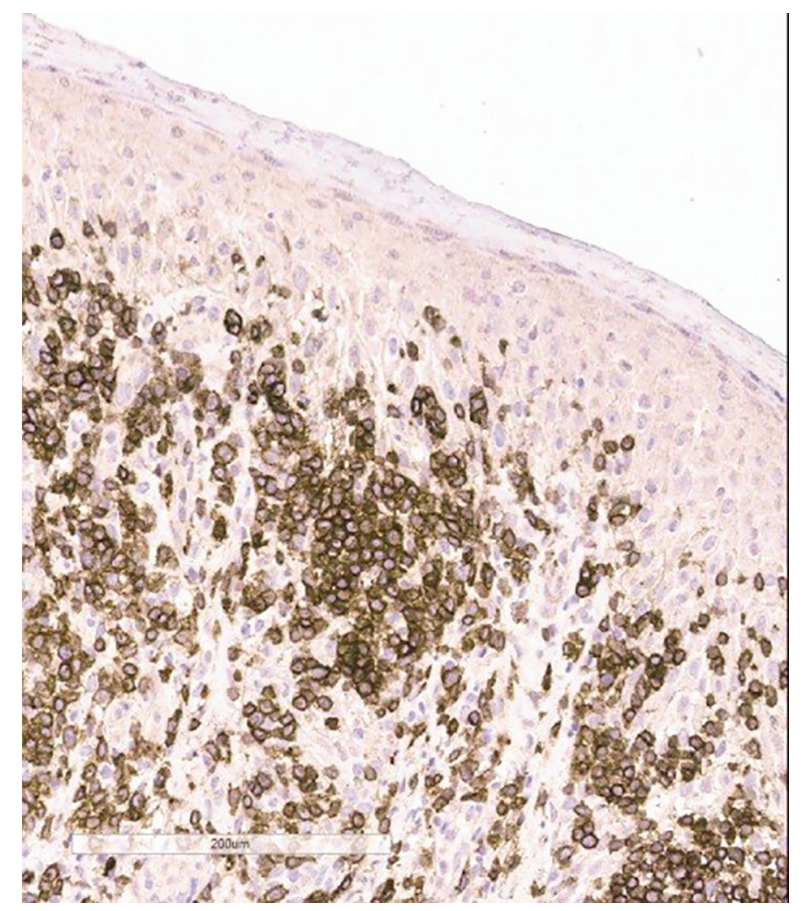

Figure 4. Skin biopsy specimen shows strong TCR gamma expression by atypical lymphocytes on immunophenotyping.

\section{References}

1. Jaffe ES. The 2008 WHO classification of lymphomas: implications for clinical practice and translational research. Hematology Am Soc Hematol Educ Program. 2009:523-531.

2. Willemze R, Jansen PM, Cerroni L, Berti E, Santucci M, Assaf C, Canninga-van Dijk MR, et al. Subcutaneous panniculitis-like T-cell lymphoma: definition, classification, and prognostic factors: an EORTC Cutaneous Lymphoma Group Study of 83 cases. Blood. 2008;111(2):838845.

3. Toro JR, Liewehr DJ, Pabby N, Sorbara L, Raffeld M, Steinberg SM, Jaffe ES. Gamma-delta T-cell phenotype is associated with significantly decreased survival in cutaneous T-cell lymphoma. Blood. 2003;101(9):3407-3412.

4. Cerroni L, Wiesner T. Cutaneous lymphomas: from morphology to chip technology. Actas Dermosifiliogr. 2009;100(Suppl 1):3-17.

5. Jones D, Vega F, Sarris AH, Medeiros LJ. CD4-CD8"Double-negative" cutaneous T-cell lymphomas share common histologic features and an aggressive clinical course. Am J Surg Pathol. 2002;26(2):225-231.

6. Arnulf B, Copie-Bergman C, Delfau-Larue $\mathrm{MH}$, Lavergne-Slove A, Bosq J, Wechsler J, Wassef M, et al. Nonhepatosplenic gammadelta T-cell lymphoma: a subset of cytotoxic lymphomas with mucosal or skin localization. Blood. 1998;91(5):1723-1731.

7. Chakrapani A, Avery A, Warnke R. Primary cutaneous gamma delta T-cell lymphoma with brain involvement and hemophagocytic syndrome. Am J Dermatopathol. 
2013;35(2):270-272.

8. Youn SH, Lee YW, Min SK, Park HR, Kim KH, Kim KJ. Fatal Cutaneous gamma/delta T-Cell Lymphoma with Central Nerve System Metastasis. Ann Dermatol. 2011;23(Suppl 1):S100-104.

9. Guizzardi M, Hendrickx IA, Mancini LL, Monti M. Cytotoxic gamma/delta subcutaneous panniculitis-like T-cell lymphoma: report of a case with pulmonary involvement unresponsive to therapy. J Eur Acad Dermatol Venereol. 2003;17(2):219-222.

10. Berti E, Tomasini D, Vermeer MH, Meijer CJ, Alessi E, Willemze R. Primary cutaneous CD8-positive epidermotropic cytotoxic T cell lymphomas. A distinct clinicopathological entity with an aggressive clinical behavior.
Am J Pathol. 1999;155(2):483-492.

11. Gaulard P, Belhadj K, Reyes F. Gammadelta T-cell lymphomas. Semin Hematol. 2003;40(3):233-243.

12. de Wolf-Peeters C, Achten R. gammadelta T-cell lymphomas: a homogeneous entity? Histopathology. 2000;36(4): 294-305.

13. Salhany KE, Macon WR, Choi JK, Elenitsas R, Lessin SR, Felgar RE, Wilson DM, et al. Subcutaneous panniculitislike T-cell lymphoma: clinicopathologic, immunophenotypic, and genotypic analysis of alpha/beta and gamma/ delta subtypes. Am J Surg Pathol. 1998;22(7):881-893.

14. Koch R, Jaffe ES, Mensing C, Zeis M, Schmitz N, Sander CA. Cutaneous gamma/delta T-cell lymphoma. J Dtsch Dermatol Ges. 2009;7(12):1065-1067. 